Silva, M.B.F.'; Carnicelli, C'; Rezende, A. C; Burgese, L.F'; Jericó, M. M. ${ }^{4}$

\section{6 - Efeitos da restrição calórica na avaliação eletrocardiográfica e da pressão arterial em cães obesos}

1- Grupo de Estudos em Obesidade Animal (ObeZoo) de Iniciação Científica do Departamento de Medicina Veterinária da Universidade Santo Amaro (UNISA), São Paulo-SP

2- Estagiária do Hospital Veterináriodo Departamento de Medicina Veterinária da Universidade Santo Amaro (UNISA), São Paulo-SP

3- Médico residente do Setor de Diagnóstico por Imagem Do Departamento de Medicina Veterinária da Universidade Santo Amaro (UNISA), São Paulo-SP

4-Coordenadora do Grupo de Estudos em Obesidade Animal (ObeZoo) de Iniciação Científica do Departamento de Medicina Veterinária da Universidade Santo Amaro (UNISA), São Paulo-SP

A presença da obesidade, doença nutricional mais freqüente em cães, predispõe o aparecimento de quadros mórbidos vários, tais como distúrbios metabólicos vários, dentre eles os problemas cardiovasculares.. Objetivou-se avaliar o efeito da restriçào calórica sobre a condiçào cardiovascular de 31 cães obesos, em condições iniciais e ao longo de cinco meses de dieta de restriçào calórica (contendo $60 \%$ das necessidades energéticas metabólicas basais), atendidos no Hospital Veterinário da UNISA, no período de fevereiro a dezembro de 2002, sendo 22 fêmeas e nove machos, seis sem raça definida (20\%), quatro poodles $(13 \%)$, quatro cocker spaniel $(13 \%)$, quatro schnauzers $(13 \%)$, dois labradores $(7 \%)$, dois pastores alemàes $(7 \%)$, e outros nove $(27 \%)$ animais de raças diversas, de faixa etária entre 3 a 11 anos. A condição de obesidade foi determinada pelo escore de condição corporal (ECC >3) e pela mensuração da porcentagem de gordura corpórea $(\% \mathrm{GC}>20 \%)$. A avaliação cardiovascular foi realizada por meio de traçado eletrocardiográfico e determinação da pressão arterial periférica, em intervalos mensais. À partir da restrição calórica, média de perda de peso obtida foi de $9 \%$ ao mês. Quando comparados os resultados iniciais das medianas e das médias de frequência cardiaca e dos valores de amplitude e duraçào das ondas $\mathrm{P}, \mathrm{Q}, \mathrm{R}, \mathrm{S}$ e T, com aqueles obtidos ao longo de cinco meses de restrição calórica, não foram constatadas diferenças estatisticamente significantes $(p>0,05$, testes de Kruskall-Wallis e ANOVA). A restrição calórica também não promoveu mudanças significantes nas alterações de ritmo ou nos distúrbios de condução, porventura exibidos nos traçados iniciais. Também nào foram observadas alterações naqueles traçados. No que tange à avaliação da pressão arterial, quando analisados os resultados individuais ao longo do periodo de restrição calórica, foi possível observar que 13 animais $(41 \%)$ apresentaram flutuações irregulares da pressão arterial sistólica, sete animais $(22 \%)$ apresentaram aumento e um animal $(3 \%)$ apresentou diminuição da pressão arterial sistólica. Em relação da pressão arterial média, dez animais $(31 \%)$ tiveram irregularidade, 8 animais $(25 \%)$ um aumento da pressão e dois animais $(6 \%)$ apresentaram diminuiçào da pressão arterial média. $\mathrm{Na}$ análise da pressão arterial diastólica, 13 animais $(41 \%)$ apresentaram irregularidade entre os meses pesquisados, sete animais $(22 \%)$ tiveram aumento e nenhum animal apresentou queda da pressão arterial diastólica. Concluiu-se que, na população de cães obesos ora estudada, a restrição calórica ao longo de cinco meses nào promove alteraçòes dignas de nota no traçado eletrocardiográfico. No que tange a avaliação da pressão arterial, à luz do método de avaliação não-invasivo utilizado, embora constatadas diferenças significantes entre os resultados obtidos ao longo da restriçào calórica, estas diferenças não sugerem tendências para a diminuiçào dos valores de pressão sistólica, diastólica ou média, como suposto pela interpretação dos dados de literatura compilados. 